\title{
Trade-off between reservoir yield and evaporation losses as a function of lake morphology in semi-arid Brazil
}

\author{
JOSÉ N.B. CAMPOS, IRAN E. LIMA NETO, TICIANA M.C. STUDART and LUIZ S.V. NASCIMENTO
}

Departamento de Engenharia Hidráulica e Ambiental, Universidade Federal do Ceará/

UFC, Campus do Pici, B1. 713, 60451-970 Fortaleza, CE, Brasil

Manuscript received on February 19, 2015; accepted for publication on June 30, 2015

\begin{abstract}
This study investigates the relationships between yield and evaporation as a function of lake morphology in semi-arid Brazil. First, a new methodology was proposed to classify the morphology of 40 reservoirs in the Ceará State, with storage capacities ranging from approximately 5 to $4500 \mathrm{hm}^{3}$. Then, Monte Carlo simulations were conducted to study the effect of reservoir morphology (including real and simplified conical forms) on the water storage process at different reliability levels. The reservoirs were categorized as convex $(60.0 \%)$, slightly convex $(27.5 \%)$ or linear $(12.5 \%)$. When the conical approximation was used instead of the real lake form, a trade-off occurred between reservoir yield and evaporation losses, with different trends for the convex, slightly convex and linear reservoirs. Using the conical approximation, the water yield prediction errors reached approximately $5 \%$ of the mean annual inflow, which is negligible for large reservoirs. However, for smaller reservoirs, this error became important. Therefore, this paper presents a new procedure for correcting the yield-evaporation relationships that were obtained by assuming a conical approximation rather than the real reservoir morphology. The combination of this correction with the Regulation Triangle Diagram is useful for rapidly and objectively predicting reservoir yield and evaporation losses in semi-arid environments.
\end{abstract}

Key words: evaporation losses, hydrological modeling, lake morphology, reservoir yield, semi-arid regions, water availability.

\section{INTRODUCTION}

Surface reservoirs constitute one of the main structural features that are created to cope with droughts in areas that are typically dry. These reservoirs are built to accommodate irregular river flows to meet the water demands of society. Since the last century, many dams (small, medium and large) have been built in semi-arid regions (Liebe et al. 2005, Pisaniello et al. 2006, Callow and Smettem 2009, Krol et al. 2011, Lima Neto et al. 2011, Malveira et al. 2012). However, in many cases, detailed information regarding the

Correspondence to: Iran Lima Neto

E-mail: iran@deha.ufc.br 
relationships between lake depth and area or volume (depth-area or depth-volume curves) is not available, which makes analyzing reservoir storage processes and estimating regulated water yields difficult.

In this context, several researchers have attempted to represent reservoir morphology using field data, empirical equations and/or satellite images. In Brazil, some studies have assessed reservoir volume using the empirical equations of Molle and Cadier (1992), who obtained data from more than 400 small dams in the Brazilian semi-arid region, as described by Lima Neto et al. (2011). Alternatively, Liebe et al. (2005) used half-pyramid methods to estimate the storage volumes of approximately 500 small reservoirs in Ghana from satellite images. By assuming that a reservoir is an inverted conical tank (see Campos 1987), Campos (2010) developed a simplified procedure (the Regulation Triangle Diagram - RTD) to predict yield, evaporation, and spill during the storage process. This method is valid for hydrologic conditions consisting of two seasonally intermittent rivers (corresponding to the conditions in Northeast Brazil and Northern Australia). Since the first edition of the Ceará State Water Resources Plan (SRH 1992), the RTD has been used to determine reservoir sizes from small, medium and large dams in semi-arid regions of Brazil.

Apart from previous studies on surface reservoirs in semiarid environments, Håkanson (1981) developed classical methodologies for analyzing lake morphology and its relationships with lake ecology (primarily focusing on natural lakes located in temperate regions). The main contributions of Håkanson (1981) included the proposed terminology and class limits for classifying lake morphology based on hypsographic curves. According to his method, lakes can be classified as very convex (VCx), convex (Cx), slightly convex (SCx), linear (L), and concave (C). The effect of such different morphologies has long been investigated in limnology (e.g., Håkanson 2004, Håkanson et al. 2004). However, to the authors' knowledge, no studies have addressed the effects of lake morphology on reservoir storage processes.

In this paper, we adapted the Håkanson (1981) morphology curves, which traditionally use lake area and depth, to use volume and depth. In addition, we developed an algorithm based on the maximum correlations between the points of a theoretical curve and the actual reservoir volume vs. depth values. Using this algorithm, we classified 40 reservoirs into the Håkanson morphological classes. Then, we used hydrological modeling to investigate the impacts of reservoir morphology (including their real forms and simplified conical shapes, as proposed by Campos (2010)) on the trade-offs between reservoir yield and evaporation losses for different reliability levels. This paper is important for the following reasons: (1) it provides a simple and accurate method for classifying the morphology of reservoirs; (2) it provides the first study that analyzes the effect of reservoir morphology on the yield-evaporation-spill relationships in reservoirs; and (3) it assesses the accuracy of the RTD procedure of Campos (2010) and proposes corrections to account for the actual conditions of real reservoirs (compared to the inverted conical tank). The methodology proposed here can be potentially used in a wide range of applications including small scale irrigation projects and plans, as well as large scale watershed planning and management.

\section{STUDY AREA AND METHODOLOGY}

The State of Ceará has an area of approximately $150,000 \mathrm{~km}^{2}$ and a population of over 8.5 million inhabitants. It is located in the semi-arid region of Brazil (Fig. 1), which is characterized by a strongly negative atmospheric water balance, where most of the rivers are seasonally intermittent and the main sources of fresh water are surface reservoirs with storage capacities that range from less than 10 to approximately $4,500 \mathrm{hm}^{3}$ (for a total of approximately 25,000 surface reservoirs, estimated from the data of Lima Neto et al. (2011)). Detailed climate and hydrological characteristics of the State of Ceará were provided by Alves et al. (2012). 


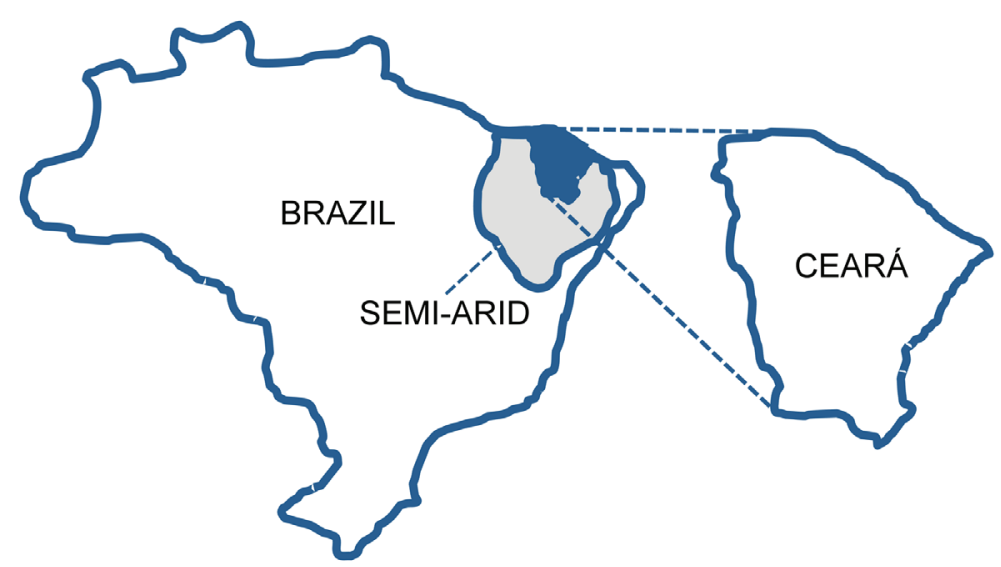

Figure 1 - Location of the State of Ceará in the semi-arid region of Brazil. (See the colors in the online version).

\section{DATA COLLECTION AND ANALYSIS}

The first stage of this study consisted of collecting and analyzing the data from the Secretaria dos Recursos Hídricos do Ceará - SRH (the State Water Resources Department), which included the following parameters for each reservoir:

a) reservoir storage capacity,

b) maximum water depth,

c) depth-volume curve,

d) monthly stream flow,

e) monthly evaporation, and

f) monthly precipitation.

Because of the availability/consistency of the data, a total of 40 reservoirs (described in Table I) were selected for the present study.

\section{RESERVOIR MORPHOLOGY}

The second stage consisted of transforming the normalized depth-area curves of Håkanson (1981) into normalized depth-volume curves using the following equation:

$$
Z_{n}-Z_{n-1}=1 / 2\left(h_{n}-h_{n-1}\right)\left(A_{n}+A_{n-1}\right)
$$

where $Z$ represents storage, $h$ is the water height related to the lowest elevation of the water in the reservoir, $A$ is the lake surface area, and $n$ refers to a particular water level. Observe that this procedure was necessary since SRH only provided depth-volume curves (rather than depth-area curves).

Figure 2(a) shows the original depth-area diagram from Håkanson (1981), which classifies the reservoirs as $\mathrm{VCx}, \mathrm{Cx}, \mathrm{SCx}, \mathrm{L}$, or C. Observe that each class represents a region between two curves (e.g., Cx reservoirs are located between F2 and F3 curves). Figure 2(b) shows the depth-volume diagram proposed here, following the same class limits defined by Håkanson (1981). Assuming that the reservoirs have a circular surface area, Figure 3 graphically depicts the form of the reservoirs by using the curves F1, F2, F3, F4, F5 and F6 shown in Figure 2(a). 

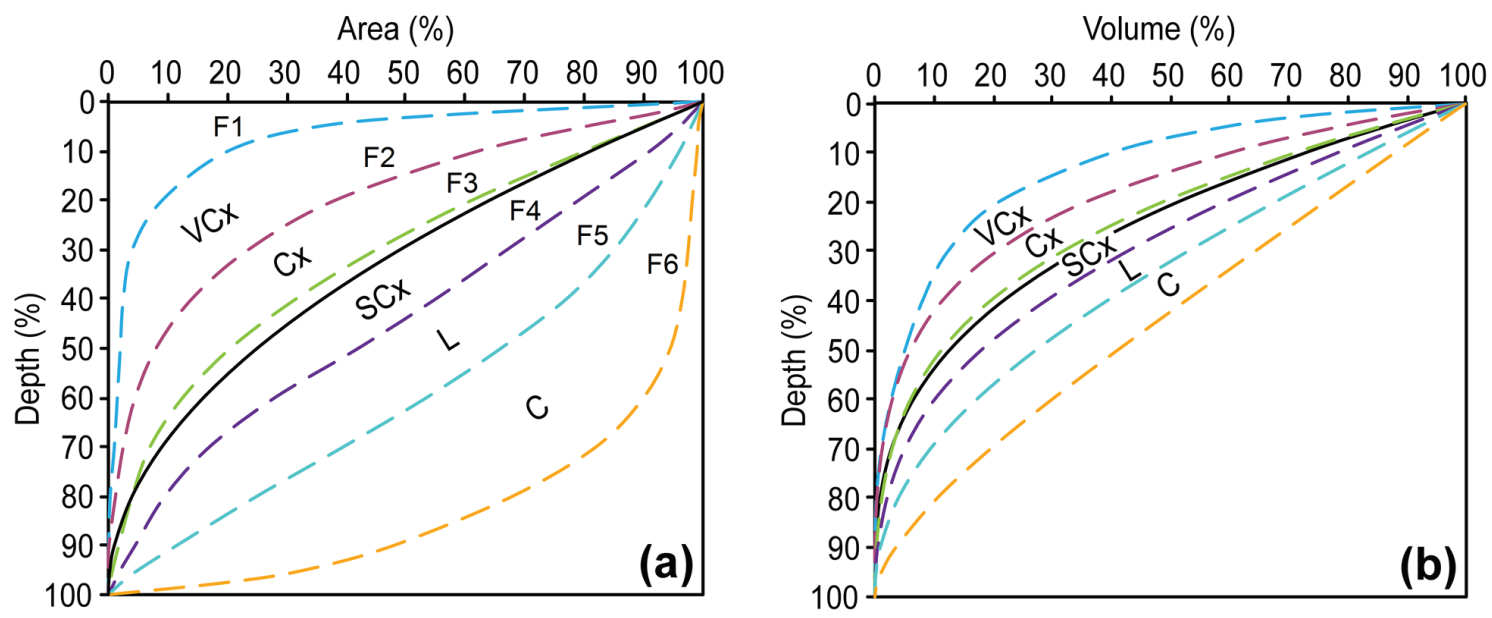

Figure 2 - Classification of the lakes as very convex - VCx (between F1 and F2 curves), convex - Cx (between F2 and F3 curves), slightly convex - SCx (between F3 and F4 curves), linear - L (between F4 and F5 curves), or concave - C (between F5 and F6 curves) according to (a) the depth-area diagram from Håkanson (1981) and (b) the proposed depthvolume diagram. Solid lines within the SCx region indicate the conical reservoir. (See the colors in the online version).
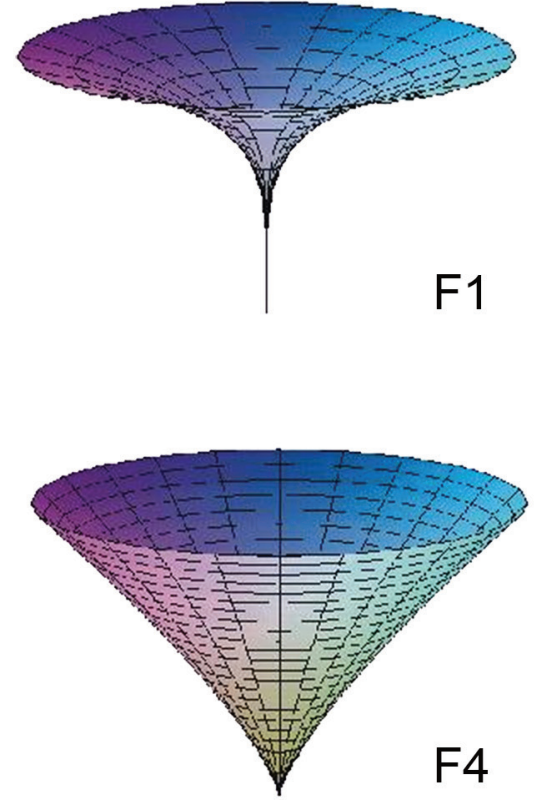

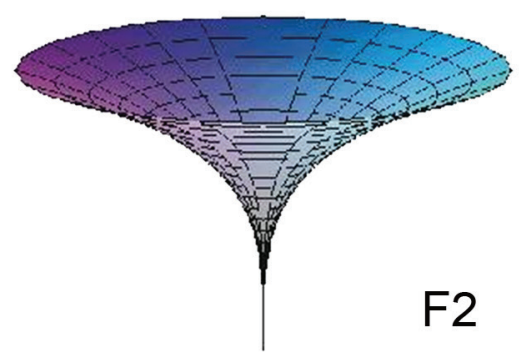

F2
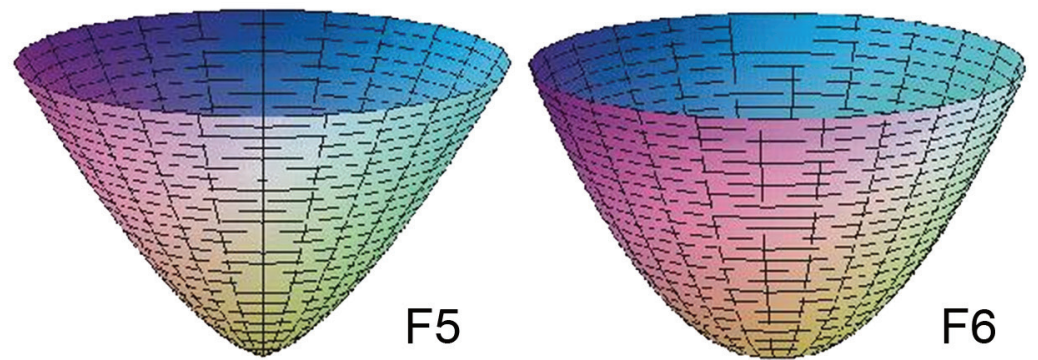

Figure 3 - Graphical representation of reservoir morphology by using the curves F1, F2, F3, F4, F5 and F6 shown in Figure 2(a) and assuming a circular surface area. (See the colors in the online version).

According to the method of Campos (2010), the reservoir morphology can be approximated as a simple conical shape based on the following relationship between the water storage capacity and water level:

$$
Z(h)=\alpha h^{3}
$$

where $\alpha$ is the reservoir shape factor given by $\alpha=K / h_{\max }{ }^{3}, K$ is the reservoir storage capacity, and $h_{\max }$ is the maximum water depth. 
Figures 2(a) and 2(b) show that the cone shape consistently falls within the slightly convex (SCx) region in the depth-area and depth-volume diagrams. To provide quantitative results, the average coefficient of determination $\left(r^{2}\right)$ between the conical reservoir curve (solid line) and the two adjacent depth-volume curves (dashed lines) [see Fig. 2(b)] can also be calculated. For conical reservoirs, the average value of $r^{2}$ (0.997) was higher for the two adjacent curves that define the SCx morphology relative to the other pairs of adjacent curves. The same procedure was conducted to classify the morphology of the 40 reservoirs that were selected for the present study. Thus, depending on the real depth-volume curve of each reservoir, the morphology could be classified as $\mathrm{VCx}, \mathrm{Cx}, \mathrm{SCx}, \mathrm{L}$, or $\mathrm{C}$, according to the average values of $r^{2}$ that were obtained for each morphology.

\section{HYDROLOGICAL MODELING}

The third stage of the study consisted of simulating the reservoir storage process by considering the original depth-volume curves and their corresponding (simplified) curves based on the conical shapes obtained using Eq. 2. The detailed steps of the simulations are outlined as follows.

We first assumed that the stream flow follows a gamma distribution function. In practice, univariate gamma distribution function is one of the most used in frequency studies (Yue et al. 2001). For yearly stream flows in semiarid regions, gamma function has been extensively used by many authors (McMahon et al. 2007a, b, Campos 2010). A recent study of Campos et al. (2014) resulted in a good agreement between observed and modelled series of inflows for the largest river in the State of Ceará (Jaguaribe River) by using gamma function. Then, assuming this type of function it was possible to generate a synthetic annual stream flow time series over at least 80 years of data ( $>50$ years, as suggested by McMahon et al. 2007a) for each reservoir. The fragment method of Svanidze (1980) was used to determine the monthly stream flow regime of the rivers. From the monthly fragments of historical data and the annual synthetic time series, we were able to generate a synthetic monthly stream flow series. Monthly averages provided by SRH were used to determine the evaporation and precipitation over the lake surfaces. Hence, using the synthetic monthly stream flow series and the average losses of the lake (evaporation minus precipitation), the reservoir budget equation given below was solved using a Monte Carlo simulation to provide the yield-evaporation-spill relationships.

$$
Z_{i+1}=Z_{i}-\left(E_{i}-P_{i}\right) \frac{1}{2}\left(A_{i+1}+A_{i}\right)+I_{i}-R_{i}-S_{i}
$$

Here, $Z_{i+1}$ and $Z_{i}$ are the reservoir volumes in months $i+1$ and $i$, respectively, $E_{i}$ is the average depth of the water evaporated from the lake surface in month $i, P_{i}$ is the average rainfall over the lake surface in month $i, A_{i+1}$ and $A_{i}$ are the lake surface areas in months $i+1$ and $i$, respectively, $I_{i}$ is the reservoir inflow in month $i, R_{i}$ is the total reservoir withdrawals in month $i$, and $S_{i}$ is the volume spilled in month $i$.

The procedure described in this study is similar to that described by Campos (2010) and Campos et al. (2014). However, different reliability levels (80, 90, 95 and 98\%) were considered in this study in addition to a large number of reservoirs (40). Furthermore, the simulations in this study were performed using both the original (real) depth-volume curves and those obtained for a conical shape. All of the simulations considered that the reservoirs were full at the beginning and that the water was uniformly released over the duration of the simulation. 


\section{ERROR ANALYSIS}

Eq. 4 is used to estimate the normalized error in the simulations of water yield that consider the conical shape instead of the real depth-volume curve:

Error $=\left[\left(\frac{\mathrm{Q}_{\text {cone }}}{\mu}-1\right)-\left(\frac{\mathrm{Q}_{\text {original }}}{\mu}-1\right)\right]$

where $Q_{\text {cone }}$ and $Q_{\text {original }}$ are the regulated water yield (associated with a reliability level) obtained by considering the inverted conical tank and the original shapes, respectively, and $\mu$ is the mean annual inflow. This equation was chosen to normalize the yield based on the mean annual inflow and to minimize discrepancies due to scale effects.

Calculating the errors using Eq. 4 also allowed us to evaluate the accuracy of the RTD procedure of Campos (2010) (which assumes that the reservoirs have a conical form) and to propose corrections for the yield-evaporation-spill relationships to account for the actual shapes of the reservoirs.

\section{RESULTS AND DISCUSSION}

Table I lists the 40 reservoirs that were selected for this study, including their storage capacity $(K)$, maximum water depth $\left(h_{\max }\right)$, shape factor $(\alpha)$, sample number of data points $(n)$, morphology classification (original depth-volume curves) based on the methodology described above, and the errors in the water yield (obtained from the inverted conical tank and real simulations) calculated using Eq. 4 for each reliability level $(80-98 \%)$. Note that all the depth-volume curves were provided by SRH. The year of surveillance refers to the date of construction of each reservoir, which ranged from 1906 (Cedro reservoir) to 2005 (Arneiroz reservoir).

TABLE I

List of the 40 reservoirs that were selected for this study, including their storage capacity $(K)$, maximum water depth $\left(h_{\max }\right)$, shape factor $(\alpha)$, sample number of data points $(n)$, classification according to morphology and the errors in the water yield for each simulated reliability level $(80-98 \%)$.

\begin{tabular}{|c|c|c|c|c|c|c|c|c|c|c|c|c|c|}
\hline \multirow{2}{*}{ Reservoir } & \multirow{2}{*}{$K\left(\mathrm{hm}^{3}\right)$} & \multirow{2}{*}{$h_{\max }(\mathrm{m})$} & \multirow{2}{*}{$\alpha$} & \multirow{2}{*}{$n$} & \multicolumn{5}{|c|}{$r^{2}$} & \multicolumn{4}{|c|}{ Error } \\
\hline & & & & & VCx & Cx & SCx & $\mathbf{L}$ & C & $80 \%$ & $90 \%$ & $95 \%$ & $98 \%$ \\
\hline R. Carvalho & 6 & 8 & 14877 & 12 & 0.943 & 0.989 & 0.997 & 0.981 & 0.938 & $0.0 \%$ & $0.8 \%$ & $0.0 \%$ & $0.0 \%$ \\
\hline Ema & 10 & 13 & 5320 & 15 & 0.933 & 0.985 & 0.997 & 0.984 & 0.943 & $0.0 \%$ & $0.0 \%$ & $0.0 \%$ & $0.0 \%$ \\
\hline Ingazeiro & 11 & 16 & 2764 & 16 & 0.902 & 0.965 & 0.992 & 0.996 & 0.974 & $-1.7 \%$ & $-1.7 \%$ & $-0.8 \%$ & $-0.8 \%$ \\
\hline M. Tabosa & 12 & 21 & 1288 & 8 & 0.950 & 0.992 & 0.995 & 0.975 & 0.927 & $0.1 \%$ & $0.0 \%$ & $0.0 \%$ & $0.0 \%$ \\
\hline R. Tanques & 13 & 12 & 7396 & 14 & 0.934 & 0.985 & 0.997 & 0.986 & 0.947 & $-3.2 \%$ & $-3.2 \%$ & $-3.2 \%$ & $-3.2 \%$ \\
\hline Trici & 17 & 17 & 3673 & 17 & 0.957 & 0.993 & 0.985 & 0.954 & 0.896 & $1.2 \%$ & $2.3 \%$ & $1.9 \%$ & $1.9 \%$ \\
\hline Cipoada & 17 & 11 & 12960 & 13 & 0.937 & 0.987 & 0.997 & 0.983 & 0.941 & $0.0 \%$ & $-0.3 \%$ & $0.0 \%$ & $-0.3 \%$ \\
\hline Pombas & 18 & 12 & 10023 & 16 & 0.945 & 0.990 & 0.996 & 0.979 & 0.934 & $1.0 \%$ & $0.0 \%$ & $1.0 \%$ & $1.0 \%$ \\
\hline Trapiá II & 18 & 24 & 1316 & 15 & 0.938 & 0.988 & 0.997 & 0.982 & 0.939 & $0.0 \%$ & $0.0 \%$ & $0.0 \%$ & $0.0 \%$ \\
\hline Olho Dágua & 21 & 23 & 1767 & 11 & 0.890 & 0.959 & 0.990 & 0.997 & 0.977 & $-1.8 \%$ & $-1.8 \%$ & $-1.8 \%$ & $-3.6 \%$ \\
\hline J. Távora & 24 & 14 & 8622 & 9 & 0.947 & 0.991 & 0.996 & 0.978 & 0.933 & $-0.6 \%$ & $0.0 \%$ & $0.0 \%$ & $-0.6 \%$ \\
\hline Puiu & 25 & 13 & 11152 & 8 & 0.930 & 0.981 & 0.997 & 0.990 & 0.957 & $-0.5 \%$ & $-1.1 \%$ & $-1.1 \%$ & $-1.3 \%$ \\
\hline T. Osterne & 28 & 25 & 1798 & 10 & 0.948 & 0.992 & 0.995 & 0.975 & 0.928 & $1.5 \%$ & $0.0 \%$ & $0.0 \%$ & $0.0 \%$ \\
\hline São José II & 29 & 17 & 5933 & 8 & 0.935 & 0.986 & 0.997 & 0.986 & 0.949 & $-2.2 \%$ & $-2.2 \%$ & $-2.2 \%$ & $-2.2 \%$ \\
\hline S. A. Russas & 30 & 10 & 29720 & 12 & 0.948 & 0.991 & 0.996 & 0.979 & 0.936 & $0.1 \%$ & $0.2 \%$ & $0.0 \%$ & $0.0 \%$ \\
\hline Prazeres & 33 & 46 & 338 & 12 & 0.961 & 0.995 & 0.991 & 0.966 & 0.914 & $0.0 \%$ & $0.0 \%$ & $1.6 \%$ & $1.6 \%$ \\
\hline
\end{tabular}


TABLE I (continuation)

\begin{tabular}{|c|c|c|c|c|c|c|c|c|c|c|c|c|c|}
\hline \multirow{2}{*}{ Reservoir } & \multirow{2}{*}{$K\left(\mathrm{hm}^{3}\right)$} & \multirow{2}{*}{$h_{\max }(\mathrm{m})$} & \multirow{2}{*}{$\alpha$} & \multirow{2}{*}{$n$} & \multicolumn{5}{|c|}{$r^{2}$} & \multicolumn{4}{|c|}{ Error } \\
\hline & & & & & VCx & Cx & SCx & $\mathbf{L}$ & C & $80 \%$ & $90 \%$ & $95 \%$ & $98 \%$ \\
\hline Jucá & 34 & 9 & 46872 & 6 & 0.912 & 0.972 & 0.994 & 0.995 & 0.969 & $-1.4 \%$ & $-1.2 \%$ & $-1.2 \%$ & $-1.2 \%$ \\
\hline Cachoeira & 34 & 18 & 5886 & 10 & 0.915 & 0.974 & 0.995 & 0.994 & 0.966 & $-6.4 \%$ & $-6.4 \%$ & $-4.8 \%$ & $-4.8 \%$ \\
\hline R. Carneiros & 37 & 34 & 946 & 14 & 0.969 & 0.995 & 0.980 & 0.944 & 0.881 & $3.1 \%$ & $6.2 \%$ & $6.2 \%$ & $9.3 \%$ \\
\hline Boa Viagem & 47 & 25 & 3008 & 16 & 0.947 & 0.988 & 0.995 & 0.981 & 0.940 & $-0.3 \%$ & $0.0 \%$ & $-0.3 \%$ & $-0.3 \%$ \\
\hline Muquem & 48 & 22 & 4586 & 7 & 0.890 & 0.961 & 0.991 & 0.996 & 0.972 & $-1.3 \%$ & $-1.3 \%$ & $-0.9 \%$ & $-0.9 \%$ \\
\hline P. Pedra & 50 & 22 & 4696 & 7 & 0.960 & 0.995 & 0.989 & 0.960 & 0.904 & $1.5 \%$ & $1.7 \%$ & $1.7 \%$ & $1.7 \%$ \\
\hline P. Barro & 52 & 15 & 15407 & 14 & 0.919 & 0.975 & 0.995 & 0.993 & 0.966 & $-2.4 \%$ & $-2.0 \%$ & $-2.0 \%$ & $-1.7 \%$ \\
\hline Várzea do Boi & 53 & 13 & 24124 & 14 & 0.947 & 0.991 & 0.994 & 0.973 & 0.923 & $1.6 \%$ & $1.6 \%$ & $1.4 \%$ & $1.4 \%$ \\
\hline Quixeramobim & 54 & 16 & 14501 & 19 & 0.941 & 0.988 & 0.997 & 0.983 & 0.942 & $-4.0 \%$ & $-0.2 \%$ & $-0.2 \%$ & $-0.2 \%$ \\
\hline Rosário & 63 & 20 & 7872 & 17 & 0.932 & 0.984 & 0.997 & 0.988 & 0.951 & $-6.3 \%$ & $-6.3 \%$ & $-8.4 \%$ & $-6.3 \%$ \\
\hline L. Campos & 64 & 12 & 34554 & 17 & $0 . \subseteq$ & & & & & & $-0.4 \%$ & $-0.4 \%$ & $-0.8 \%$ \\
\hline Canoas & 69 & 43 & 871 & 11 & 0.983 & 0.991 & 0.965 & 0.921 & 0.852 & $5.6 \%$ & $5.1 \%$ & $5.1 \%$ & $4.6 \%$ \\
\hline Patu & 72 & 30 & 2660 & 21 & 0.964 & 0.996 & 0.989 & 0.962 & 0.907 & $0.5 \%$ & $1.2 \%$ & $0.6 \%$ & $0.7 \%$ \\
\hline Atalho II & 108 & 35 & 2525 & 8 & 0.907 & 0.968 & 0.993 & 0.995 & 0.973 & $-1.0 \%$ & $-1.0 \%$ & $-1.0 \%$ & $-0.9 \%$ \\
\hline Cedro & 126 & 15 & 37333 & 16 & 0.916 & 0.974 & 0.995 & 0.994 & 0.967 & $-5.5 \%$ & $-6.2 \%$ & $-6.2 \%$ & $-5.5 \%$ \\
\hline Bastiões & 137 & 32 & 4172 & 9 & 0.941 & 0.989 & 0.997 & 0.981 & 0.938 & $0.0 \%$ & $0.0 \%$ & $0.0 \%$ & $0.0 \%$ \\
\hline Arneiroz & 190 & 23 & 15079 & 9 & 0.938 & 0.987 & 0.997 & 0.985 & 0.944 & $0.0 \%$ & $-0.1 \%$ & $-0.1 \%$ & $0.0 \%$ \\
\hline Farias Brito & 198 & 50 & 1619 & 15 & 0.979 & 0.990 & 0.976 & 0.945 & 0.890 & $0.0 \%$ & $0.0 \%$ & $0.0 \%$ & $0.0 \%$ \\
\hline Trussu & 263 & 32 & 8026 & 33 & 0.932 & 0.986 & 0.997 & 0.984 & 0.943 & $0.3 \%$ & $0.1 \%$ & $0.0 \%$ & $0.0 \%$ \\
\hline P. Brancas & 434 & 27 & 22052 & 16 & 0.979 & 0.994 & 0.971 & 0.930 & 0.863 & $5.0 \%$ & $4.7 \%$ & $4.5 \%$ & $4.3 \%$ \\
\hline Aurora & 873 & 35 & 20362 & 8 & 0.948 & 0.990 & 0.996 & 0.980 & 0.938 & $-0.5 \%$ & $-0.4 \%$ & $-0.6 \%$ & $-0.4 \%$ \\
\hline Banabuiú & 1800 & 56 & 10529 & 21 & 0.964 & 0.995 & 0.990 & 0.966 & 0.917 & $-0.5 \%$ & $-1.3 \%$ & $-0.4 \%$ & $0.5 \%$ \\
\hline Orós & 1956 & 38 & 37096 & 13 & 0.973 & 0.996 & 0.982 & 0.948 & 0.889 & $3.3 \%$ & $4.6 \%$ & $5.2 \%$ & $6.1 \%$ \\
\hline Castanhão & 4450 & 45 & 48834 & 8 & 0.958 & 0.994 & 0.992 & 0.970 & 0.921 & $-0.7 \%$ & $-0.4 \%$ & $-0.3 \%$ & $-0.2 \%$ \\
\hline
\end{tabular}

Figure 4 shows an example of reservoir classifications, including Trici and Castanhão as $\mathrm{Cx}, \mathrm{R}$. Carvalho and Aurora as SCx, and Ingazeiro and Atalho II as L. All of the reservoirs listed in Table I presented a maximum coefficient of determination $\left(r^{2}\right)$ that was greater than 0.99 , which gives credence to the methodology proposed herein for classifying reservoir morphology.

As summarized in Figure 5, most reservoirs were classified as SCx (60.0\%), followed by Cx (27.5\%) and L (12.5\%). No reservoirs were classified as VCx or C. Because the conical shape was classified as SCx (Fig. 2), most of the reservoirs evaluated here (also classified as SCx) should behave similarly to a conical reservoir. In addition, no general trend was observed for the reservoir morphology as a function of storage capacity, maximum water depth or the shape factor.

Figures 6 and 7 show typical results of the Monte Carlo simulation of yield-evaporation-spill for different reliability levels (80 - 98\%) and different reservoirs [Trici (classified as Cx) and Atalho II (classified as L)] considering their original depth-volume curves and their simplified curves given by Eq. 2 (conical shape). As expected, the regulated water yield decreased with the reliability level, while the evaporation and spill losses increased in both reservoirs. By contrast, when the conical shape was used instead of the original convex reservoir (Trici), the annual water yield increased by approximately $0.5 \mathrm{hm}^{3}$ while the evaporation decreased by approximately $0.5 \mathrm{hm}^{3}$; thus, the spill losses remained approximately constant (for the same reliability level). By contrast, when the cone was used instead of the original linear reservoir (Atalho II), the annual water yield decreased by approximately $1.0 \mathrm{hm}^{3}$ and the evaporation increased by approximately $1.0 \mathrm{hm}^{3}$; thus, the spill losses remained constant. Similar behaviors were obtained for the other reservoirs listed in Table I. Thus, a trade-off occurred between yield and evaporation when the conical 

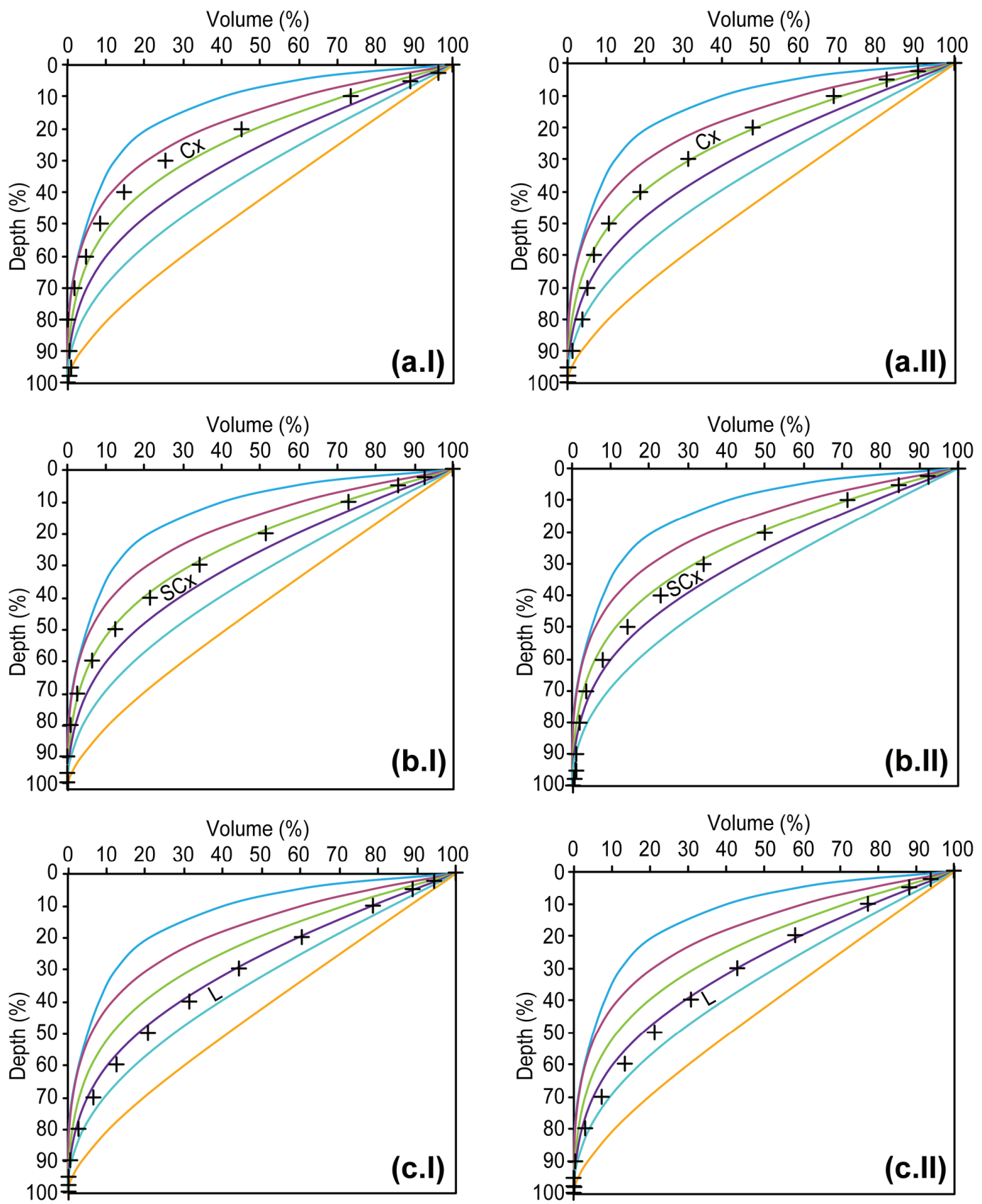

Figure 4 - Example of reservoir classification according to their depth-volume curves (represented by crosses): (a.I) Trici and (a.II) Castanhão as convex (Cx); (b.I) R. Carvalho and (b.II) Aurora as slightly convex (SCx); and (c.I) Ingazeiro and (c.II) Atalho II as linear (L). (See the colors in the online version).

approximation was used instead of the real reservoir morphology, but with different trends for convex and linear shapes (inversely related). Based on Figure 8, in which the reservoirs with different morphologies ( $\mathrm{Cx}, \mathrm{SCx}$ and $\mathrm{L}$ ) and the same storage capacities and maximum water depths (i.e., the same values of $\alpha$ ), the reservoirs present different surface areas and different evaporation losses. Hence, Cx reservoirs tend to present higher evaporation losses than conical reservoirs, while the opposite result occurs in L reservoirs. 
By contrast, SCx reservoirs generally present slightly lower evaporation losses than conical reservoirs. Figure 8 was obtained by converting the depth-area curves from Håkanson (1981) [see Fig. 2(a)] into a depth-diameter diagram by assuming that the reservoir diameter was proportional to the square of the lake surface area (see Figure 3).

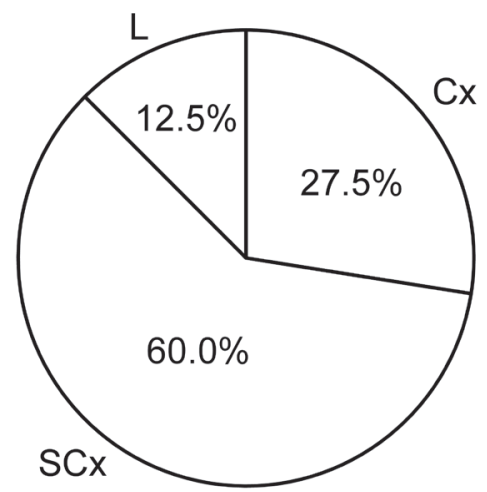

Figure 5 - Percent of reservoirs in each morphology class (convex - Cx, slightly convex - SCx, and linear - L).
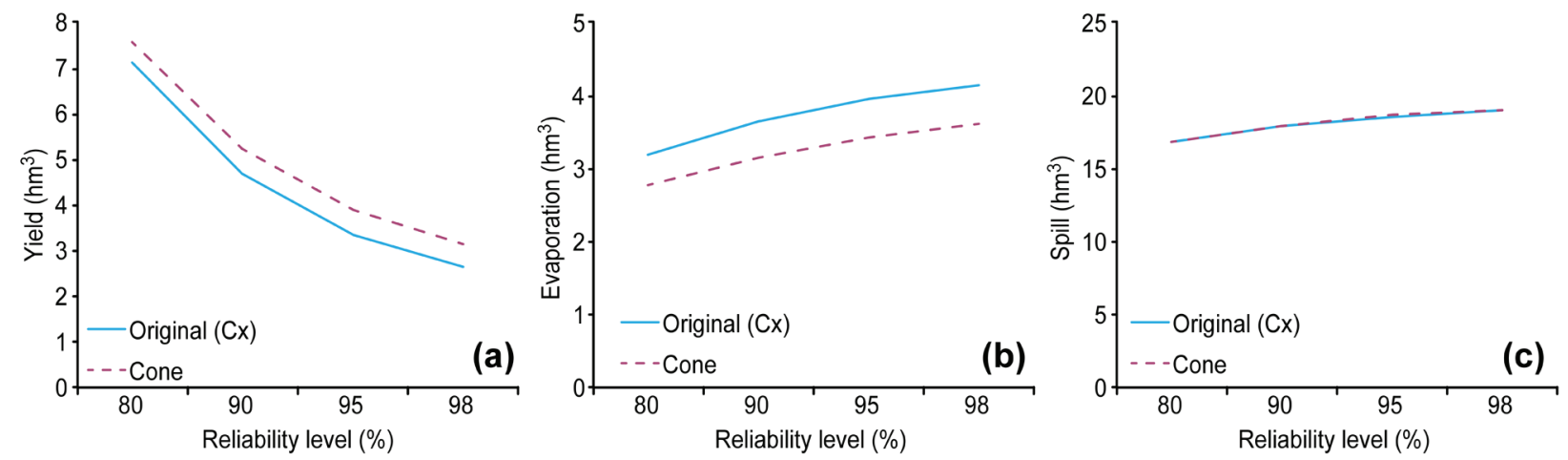

Figure 6 - Monte Carlo simulation for the Trici reservoir considering its original (convex - Cx shape) and simplified conical depthvolume curves for different reliability levels (80, 90, 95, and 98\%): (a) annual water yield; (b) annual evaporation losses; and (c) annual spill losses. (See the colors in the online version).
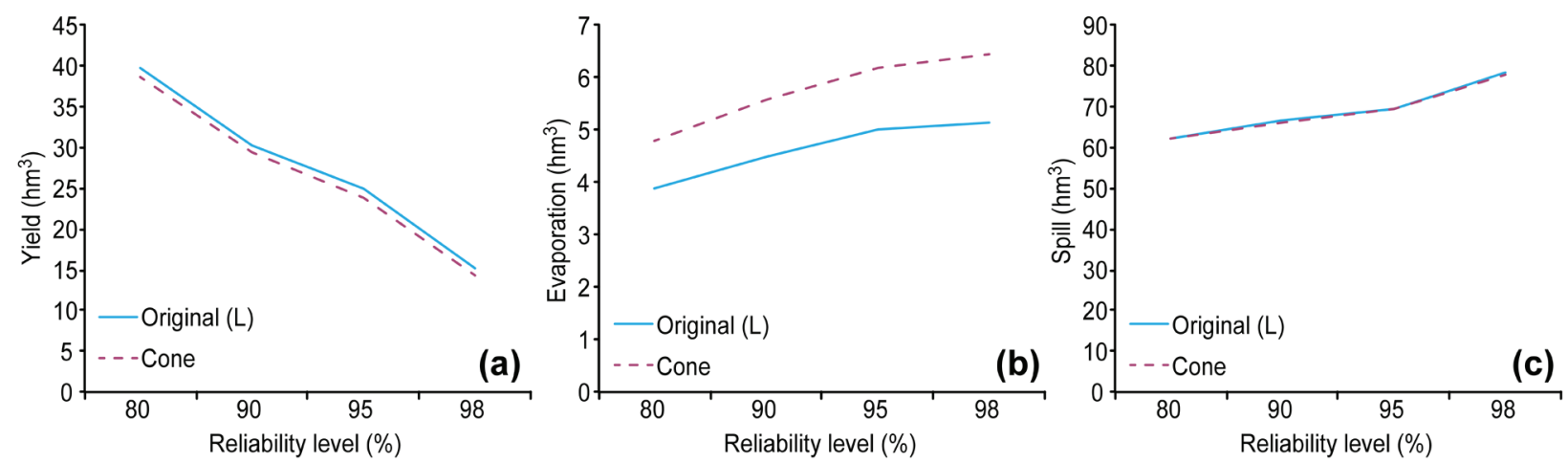

Figure 7 - Monte Carlo simulation for the Atalho II reservoir considering its original (linear - L shape) and simplified conical depth-volume curves for different reliability levels (80, 90, 95, and 98\%): (a) annual water yield; (b) annual evaporation losses; and (c) annual spill losses. (See the colors in the online version). 


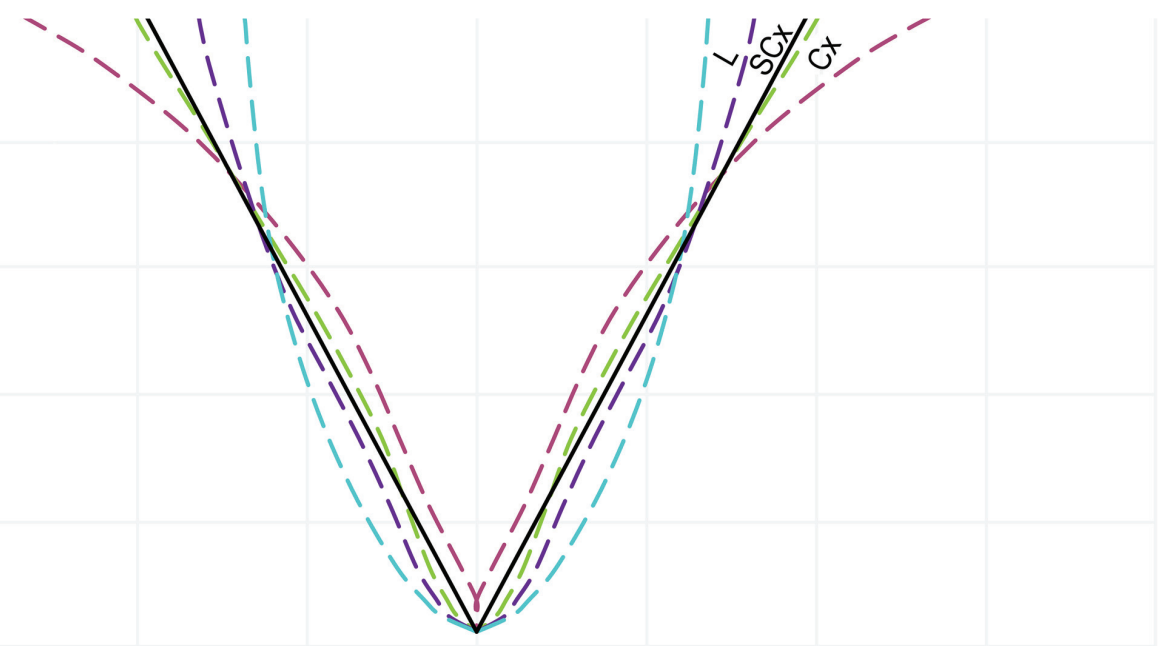

Figure 8 - Depth-diameter diagram converted from the depth-area curves of Håkanson (1981) [see Fig. 2(a)], which assumes that the reservoir diameter is proportional to the square of lake surface area. The curves indicate reservoirs with different morphologies ( $\mathrm{Cx}, \mathrm{SCx}$ and $\mathrm{L})$, but with the same storage capacities and maximum water depths (i.e., the same values of $\alpha$ ). Solid lines represent a conical reservoir. (See the colors in the online version).

Figure 9 shows the average bias errors in water yield (with bars representing the standard deviations) that were obtained by comparing the simulation results for the conical approximation and the real morphologies (SCx, Cx, and L) [see Eq. (3)] for all of the reservoirs listed in Table I at different reliability levels $(80-98 \%)$. Average biases of $+1.75,+2.07,+2.16$, and $+2.42 \%$ of the mean annual inflow $\mu$ were obtained when comparing the conical approximation to the Cx reservoirs for reliabilities of $80,90,95$, and $98 \%$, respectively. Thus, such an approximation overestimates the water yield, which slightly increased with the reliability level. By contrast, average biases of $-1.29,-1.27,-1.12$, and $-1.29 \%$ were obtained when comparing the conical approximation to the L reservoirs. In contrast with the convex reservoirs, this approximation underestimates the water yield that and does not follow any clear trend relative to the reliability level. Finally, average biases of $-1.09,-1.04,-1.05$, and $-1.02 \%$ were obtained for the SCx reservoirs with a behavior that was similar to that of the L reservoirs (but with smaller errors). For all of the above cases, the average bias in the water yield was compensated for by the average bias (with the opposite signal) in the evaporation losses, while the spill losses remained nearly constant for the different reservoir morphologies (original and conical forms). Therefore, it is possible to use the aforementioned biases to verify the accuracy of the RTD procedure of Campos (2010) and to propose corrections to account for the actual shape of the reservoirs (as compared to the conical form).

Regarding the accuracy of the RTD approach of Campos (2010), the standard deviations shown in Figure 9 indicate that the errors in predicting the water yield by assuming the conical approximation may be up to $\pm 5 \%$ of the mean annual inflow $\mu$. Note that this error did not present any trends with reservoir size or other variables evaluated in the present study (see Table I). For larger reservoirs (with large storage capacities $K$ compared to $\mu$ ), where up to $70 \%$ of $\mu$ is regulated (for the present study), the above-mentioned 

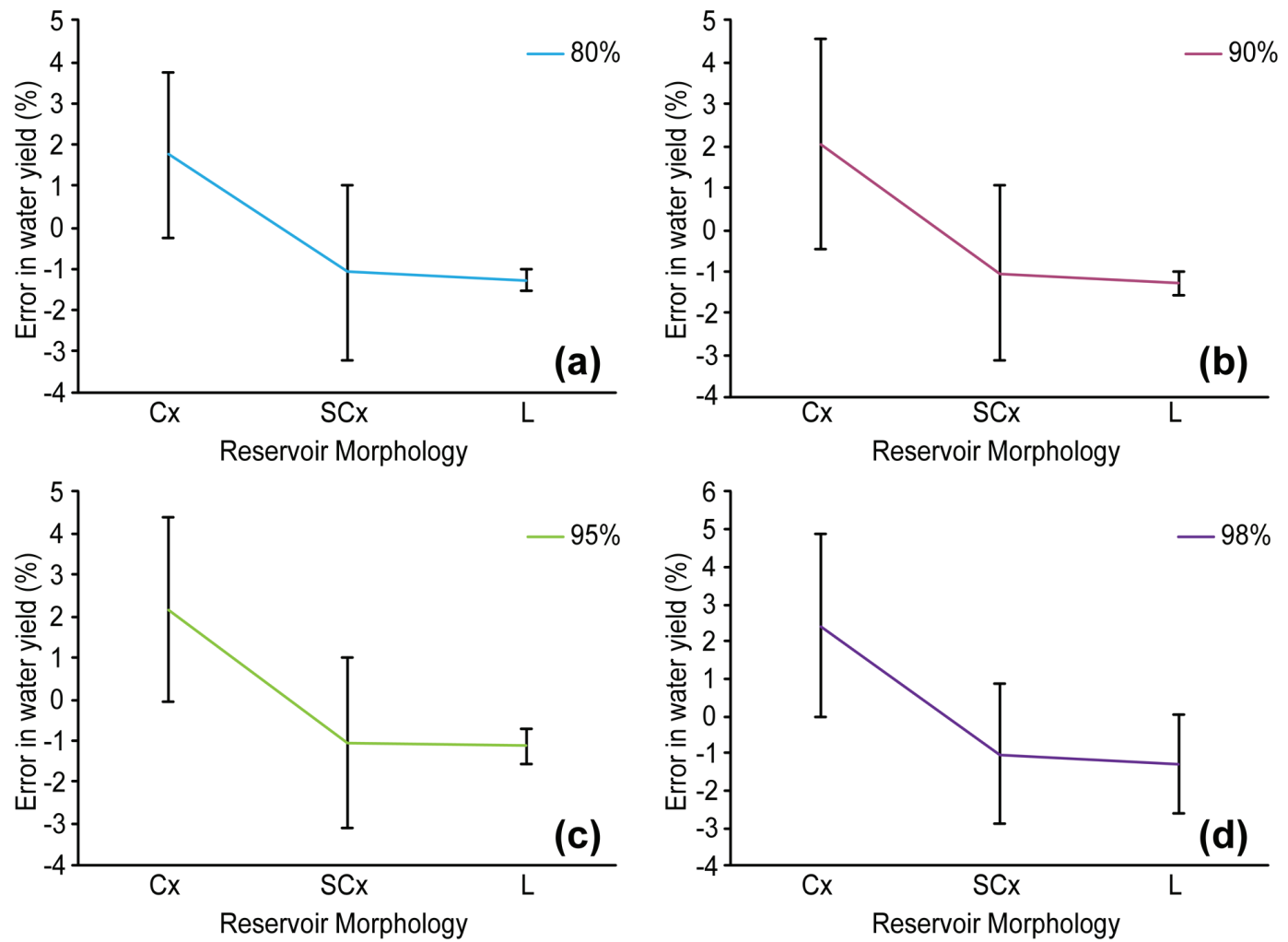

Figure 9 - Average bias errors in water yield (bars indicate the standard deviations) obtained by comparing the simulation results for the conical approximation and the real morphologies $(\mathrm{Cx}, \mathrm{SCx}$, and $\mathrm{L})$ for all reservoirs listed in Table I at different reliability levels: (a) 80, (b) 90, (c) 95 and (d) 98\%. (See the colors in the online version).

error (5\%) may be ignored. By contrast, for smaller reservoirs (with small $K$ with respect to $\mu$ ), the error may be relevant because regulated water yields that were as low as $10 \%$ of $\mu$ were found herein. However, corrections can be made to the RTD procedure if the original depth-volume curve is available to classify the reservoir according to its morphology following the methodology described in this study.

The first edition of the Ceará State Water Resources Plan (SRH 1992), as well as the subsequent State Decree (\# 23067/94), established a reliability level of $90 \%$ as the main reference for water allocation. Thus, by considering this reliability level as an example, the corrections for the RTD approach of Campos (2010) can be expressed as follows:

a) From conical to $\mathrm{Cx}$ reservoirs:

- Yield $(\mathrm{Cx})=$ Yield (Cone) $-2.07 \% \mu$;

- Evaporation $(\mathrm{Cx})=$ Evaporation $(\mathrm{Cone})+2.07 \% \mu$;

- Spill $(\mathrm{Cx})=\operatorname{Spill}$ (Cone)

b) From conical to $\mathrm{SCx}$ reservoirs:

- Yield $(\mathrm{SCx})=$ Yield (Cone) $+1.04 \% \mu$;

- Evaporation $(\mathrm{SCx})=$ Evaporation $(\mathrm{Cone})-1.04 \% \mu$;

- Spill (SCx) = Spill (Cone)

c) From conical to L reservoirs:

- Yield $(\mathrm{L})=$ Yield $($ Cone $)+1.27 \% \mu$; 
- Evaporation (L) = Evaporation (Cone) - 1.27\%

- $\quad$ Spill (L) = Spill (Cone)

Note that similar corrections can be performed for the other reliability levels (80, 95, and 98\%) using their corresponding biases (already calculated in this study).

\section{APPLICATION}

The methodology and results obtained here can be used to correct (from the conical to the actual reservoir shape) the water yield predicted from the RTD of Campos (2010). The M. Tabosa reservoir (Table I) can be used as an example. This relatively small reservoir has a storage capacity of $K=12.1 \mathrm{hm}^{3}$ and a maximum water depth of $h_{\max }=21.1 \mathrm{~m}(\alpha=1288.1)$. Its mean annual inflow is $\mu=248.0 \mathrm{hm}^{3}$, and its regulated yield with $90 \%$ reliability is $Q_{\text {cone }}=14.0 \mathrm{hm}^{3}$ (estimated from the RTD). Thus, using the depth-volume curve of this reservoir and the methodology proposed here, M. Tabosa can be classified as a SCx reservoir. Then, using the relationship Yield $(\mathrm{SCx})=$ Yield (Cone) $-1.04 \% \mu$ (given above), the regulated yield can be corrected to $Q_{S C x}=11.4 \mathrm{hm}^{3}$ (approximately $20 \%$ smaller than $Q_{\text {cone }}$ ). Note that this error decreases as the capacity-to-inflow ratio increases, which normally occurs for larger reservoirs.

\section{CONCLUSIONS}

This study presents a new contribution for the classification of lake morphology and analysis of its impact on reservoir yield and evaporation losses. Of the 40 reservoirs selected, $60.0 \%$ were classified as slightly convex (SCx), $27.5 \%$ as convex $(\mathrm{Cx})$, and $12.5 \%$ as linear (L). The Monte Carlo simulation for different reliability levels $(80,90,95$, and $98 \%)$ showed that the $\mathrm{Cx}$ reservoirs generally presented lower water yields than conical reservoirs with the same storage capacities and maximum water depths. This result occurred because of their higher evaporation losses. The opposite trend occurs with SCx and L reservoirs. The results indicated a clear trade-off between reservoir yield and evaporation losses when the conical approximation was used instead of the real reservoir morphology, as spill remained constant for each reliability level. The errors in estimating the water yield by assuming the conical approximation were up to $5 \%$ of the mean annual inflow. For large reservoirs with high capacity-to-inflow ratios, where up to $70 \%$ of the mean annual inflow was regulated, this error may be negligible. By contrast, for smaller reservoirs with low capacityto-inflow ratios, this error may be important because regulated yields as low as approximately $10 \%$ of the inflow were found. Finally, for each reliability level, we present a procedure for correcting the obtained yield-evaporation-spill relationships by assuming a conical approximation rather than using the actual shape of the reservoirs. When this correction is used with the Regulation Triangle Diagram - RTD from Campos (2010), it can easily predict the yield-evaporation-spill in the reservoir storage process in semi-arid regions, such as Northeast Brazil and Northern Australia. Overall, the methodology proposed herein can be applied in many practical situations ranging from small scale irrigation plans to large scale watershed plans.

\section{RESUMO}

Este estudo investiga as relações entre vazão e evaporação em função da morfologia de lagos em uma região semiárida do Brasil. Inicialmente, foi proposta uma nova metodologia para classificar a morfologia de 40 reservatórios no Estado do Ceará, com capacidades de armazenamento variando entre aproximadamente 5 e $4500 \mathrm{hm}^{3}$. Em seguida, foram realizadas simulações do tipo Monte Carlo para estudar o efeito da morfologia do reservatório (incluindo suas 
formas reais e cônicas simplificadas) sobre o processo de armazenamento de água em diferentes níveis de garantia. Os reservatórios foram classificados como convexos (60,0\%), ligeiramente convexos (27,5\%) ou lineares $(12,5 \%)$. Quando a aproximação cônica foi usada em vez de a forma real do lago, ocorreu uma compensação entre vazão e perdas por evaporação com diferentes tendências para os reservatórios convexos, ligeiramente convexos e lineares. Usando a aproximação cônica, os erros na previsão da vazão da água foram de aproximadamente $5 \%$ da média da vazão anual afluente, o que pode ser considerado insignificante para grandes reservatórios. No entanto, para reservatórios menores, este erro se tornou relevante. Portanto, este trabalho apresenta um novo procedimento para corrigir as relações entre vazão-evaporação que foram obtidas assumindo uma aproximação cônica, em vez de a morfologia real do reservatório. A combinação desta correção com o Diagrama Triangular de Regularização é útil para predizer rápida e objetivamente as perdas de vazão e evaporação do reservatório em ambientes semiáridos.

Palavras-chave: perdas por evaporação, modelagem hidrológica, morfologia de lagos, vazão regularizada, regiões semiáridas, disponibilidade hídrica.

\section{REFERENCES}

ALVES JMB, CAMPOS JNB AND SERVAIN J. 2012. Reservoir management using coupled atmospheric and hydrological models: The Brazilian semi-arid case. Water Resour Manag 1: 1365-1385.

CALLOW JN AND SMETTEM KRJ. 2009. The effect of farm dams and constructed banks on hydrologic connectivity and runoff estimation in agricultural landscapes. Environ Model Software 24: 959-968.

CAMPOS JNB. 1987. A procedure for reservoir sizing on intermittent rivers under high evaporation rate. PhD Dissertation, Colorado State University, Fort Collins.

CAMPOS JNB. 2010. Modeling the yield-evaporation-spill in the reservoir storage process: The Regulation Triangle Diagram. Water Resour Manag 24: 3487-3511.

CAMPOS JNB, SOUZA FILHO FA AND LIMA HVC. 2014. Risks and uncertainties in reservoir yield in highly variables intermittent rivers: the Castanhão reservoir case in Brazilian semiarid. Hydrolog Sci J 59: 1184-1195.

HÅKANSON L. 1981. A manual of lake morphometry. Springer Verlag, Berlin.

HÅKANSON L. 2004. Lakes: form and function. The Blackburn Press, New Jersey.

HÅKANSON L, BLENCKNER T AND MALMAEUS M. 2004. New, general methods to define the depth separating surface water from deep water, outflow and internal loading for mass-balance models for lakes. Ecol Model 175: 339-352.

KROL MS, VRIES MJ, OEL PR AND ARAÚJO JC. 2011. Sustainability of small reservoirs and large scale water availability under current conditions and climate change. Water Resour Manag 25: 3017-3026.

LIEBE J, VAN DE GIESEN N AND ANDREINI M. 2005. Estimation of small reservoir storage capacities in a semi-arid environment: A case study in the Upper East Region of Ghana. Phys Chem Earth 30: 448-454.

LIMA NETO IE, WIEGAND MC AND ARAÚJO JC. 2011. Sediment redistribution due to a dense reservoir network in a large semiarid Brazilian basin. Hydrolog Sci J 56: 319-333.

MALVEIRA VTC, ARAÚJO JC AND GUENTNER A. 2012. Hydrological impact of a high-density reservoir network in the semiarid north-eastern Brazil. J Hydrol Eng 17: 109-117.

MCMAHON T, PEGRAM GGS, VOGEL RM AND PEEL MC. 2007a. Revisiting reservoir storage-yield relationships using a global stream flow database. Adv Water Resour 30: 1858-1872.

McMahon T, Vogel RM, Peel MC And Pegram GGS. 2007b. Global streamflows - Part 1: Characteristics of annual streamflows. J Hydrol 347: 243-259.

MOLLE F AND CADIER E. 1992. Manual do pequeno açude. SUDENE, Recife.

PISANIELLO JD, ZHIFANG W AND MCKAY JM. 2006. Small dams safety issues - engineering/policy models and community responses from Australia. Water Policy 8: 81-95.

SRH. 1992. Plano stadual de recursos hídricos. Secretaria de Recursos Hídricos do Estado do Ceará - SRH, Fortaleza.

SVANIDZE G. 1980. Mathematical modeling of hydrological series for hydroeletric and water resources computations. Water Resources Publications, Fort Collins.

YUE S, OUARDA TBMJ AND BOBÉE B. 2001. A review of bivariate gamma distribution for hydrological applications. J Hydrol 246: 1-18. 
